\title{
Surface chemistry during plasma etching of silicon
}

\author{
V. M. Donnelly, I. P. Herman ${ }^{\mathrm{a}}$, C. C. Cheng ${ }^{\mathrm{b}}$, and K. V. Guinn \\ AT\&T Bell Laboratories, 600 Mountain Ave., Murray Hill, NJ 07974
}

\begin{abstract}
Angle-resolved x-ray photoelectron spectroscopy (XPS) and laserinduced thermal desorption (LD), combined with laser-induced fluorescence (LIF) detection, were used to study the etching of polycrystalline Si (poly-Si) and single crystal $\mathrm{Si}(100)$ in high density $\left(1-2 \times 10^{11}\right.$ ions $\left./ \mathrm{cm}^{3}\right)$, low pressure (0.5-10 mTorr) $\mathrm{Cl}_{2} / \mathrm{HBr}$-containing, helical resonator plasmas. The XPS measurements on both unmasked $\mathrm{Si}(100)$ and fine-line masked poly-Si samples were performed after the sample was etched and then transferred under high vacuum from the plasma reactor to the ultrahigh vacuum (UHV) analysis chamber. The LD-LIF measurements on unmasked $\mathrm{Si}(100)$ samples were performed in-situ during etching. In these experiments, $\mathrm{XeCl}$ excimer laser pulses rapidly heat the $\mathrm{Si}$ surface to near the melting point, causing thermal desorption of $\mathrm{SiCl}$. The tail of the same laser pulse excites $\mathrm{SiCl}$ to the $\left(\mathrm{B}^{2} \Sigma^{+}\right)$ state in the gas-phase near the surface. The subsequent fluorescence signal from this state is proportional to $\mathrm{Cl}$-coverage, verified by XPS. In $\mathrm{HBr}$ containing plasmas, analogous LD-LIF detection was used for $\mathrm{SiBr}$, providing a measure of $\mathrm{Br}$ coverage. The major findings of these studies are that $\mathrm{Si}$ surfaces rapidly become covered with a stable (in vacuum), saturated layer of about 2 monolayers of halogens during plasma etching. The layer consists of silicon mono-, di-, and tri-halides. In $\mathrm{Cl}_{2}$ plasmas, the $\mathrm{Cl}$ coverage increases with increasing ion energy, but is nearly independent of pressure (0.5-20 mTorr). Chlorination occurs rapidly with respect to the time required to etch one monolayer, at pressures as low as $0.5 \mathrm{mTorr}$. Consequently, the etching rate is limited by the ion flux, and not the neutral flux under these conditions. In mixed $\mathrm{Cl}_{2} / \mathrm{HBr}$ plasmas, the coverages of $\mathrm{Cl}$ and $\mathrm{Br}$ are simply proportional to the total respective halogen content of the feed gas. Other implications for etching mechanisms are discussed.
\end{abstract}

\section{INTRODUCTION}

Despite considerable effort, plasma etching mechanisms are still not well understood. In particular, deviations from ideal anisotropic etching are often observed and are the subject of many current investigations. Most experimental and theoretical studies have dealt with the gas-phase plasma physics and chemistry. Fewer studies have been performed on plasma-surface interactions, and most of these have either carried out surface analysis after etching, or have simulated plasma conditions in high-vacuum beam experiments. This high vacuum, non-plasma environment is necessary to allow conventional electron-detection-based surface analysis techniques to be used. To understand and better control etching processes, real-time surface diagnostic techniques are required that are not based on electron spectroscopy. Infrared (IR) optical absorption is one possible technique that can be applied, and one study of etching of $\mathrm{Si}$ in a chlorine plasma has recently been published (1). Surface IR absorption is weak, however, and $\mathrm{Si}-\mathrm{Cl}$ vibrational frequencies are low, so that special wedged substrates with buried metal layers are required to obtain sufficient sensitivity. Recently, we reported a laser desorptionlaser induced fluorescence (LD-LIF) technique for measuring $\mathrm{Cl}$ and $\mathrm{Br}$ coverages on Si during etching in high-density $\mathrm{HBr} / \mathrm{Cl}_{2}$ plasmas (2)-(4). Laser pulses are used to rapidly heat the surface and desorb Simonohalide which is in turn detected by laser-induced fluorescence. The LD-LIF technique can be 
applied at the pressures typically used in plasma etching, as well as at higher pressures and is capable of detecting coverages of $<0.1$ monolayers with a time resolution of less than $0.02 \mathrm{~s}$. A description of this technique and selected applications from recent reports (2)-(4) are summarized here.

\section{EXPERIMENTAL PROCEDURE}

The plasma reactor consists of a helical resonator source and a stainless steel downstream chamber (2)(6). The substrate stage is radio-frequency ( $\mathrm{rf}$ ) biased to achieve DC bias voltages of $0-120 \mathrm{~V}$. The charge density above the $\mathrm{Si}$ substrate in the downstream chamber was $1-2 \times 10^{11} \mathrm{~cm}^{-3} . \mathrm{Cl}_{2} / \mathrm{HBr}$ total flow rates of 2-17 sccm and pressures of $0.6-20 \mathrm{mTorr}$ were used. $\mathrm{The}_{2} /\left(\mathrm{HBr}+\mathrm{Cl}_{2}\right)$ ratio was varied from 0 to 1 . Polycrystalline $\mathrm{Si}$ (poly-Si) and single crystal $\mathrm{Si}(100)$ substrates were used. A UHV loadlock chamber connects the plasma reactor to a UHV analysis chamber, allowing samples to be transferred to this chamber after etching, without exposure to air. Angle-resolved x-ray photoelectron spectroscopy (XPS) measurements are performed in this analysis chamber. The LD-LIF detection apparatus is mounted on the plasma chamber. It consists of a $\mathrm{XeCl}$ excimer laser, imaging optics to collect the fluorescence, and a monochromator equipped with a photomultiplier tube. The laser beam passes through a viewport at the top of the plasma source and irradiates the sample at normal incidence. The fluorescence from the near-surface region is imaged onto the entrance slit of the monochromator.

\section{RESULTS AND DISCUSSION}

After etching, angle-resolved XPS measurements on masked samples used shadowing of photoelectrons by adjacent features and differential electrostatic charging (5), (6), (7) to distinguish adsorbates on the photoresist (PR) -masked surfaces from those on etched Si sidewalls and trench bottoms. These results are discussed in detail elsewhere (5), (6). In pure $\mathrm{Cl}_{2}$ plasmas, about 2 monolayers of $\mathrm{Cl}$ was found on all 4 surfaces (i.e. PR and poly-Si vertical and horizontal surfaces). No carbon was detected on the poly-Si surfaces, however, a thin coverage of $\mathrm{Si}$ was found on the PR sidewall. Analogous results were obtained in pure $\mathrm{HBr}$ plasmas. High resolution $\mathrm{Si}(2 \mathrm{p})$ spectra revealed that $\mathrm{Si}-$ mono, di, and tri-halides were present. A sample spectrum recorded after etching in a $\mathrm{Cl}_{2}$ plasma is shown in Figure 1.

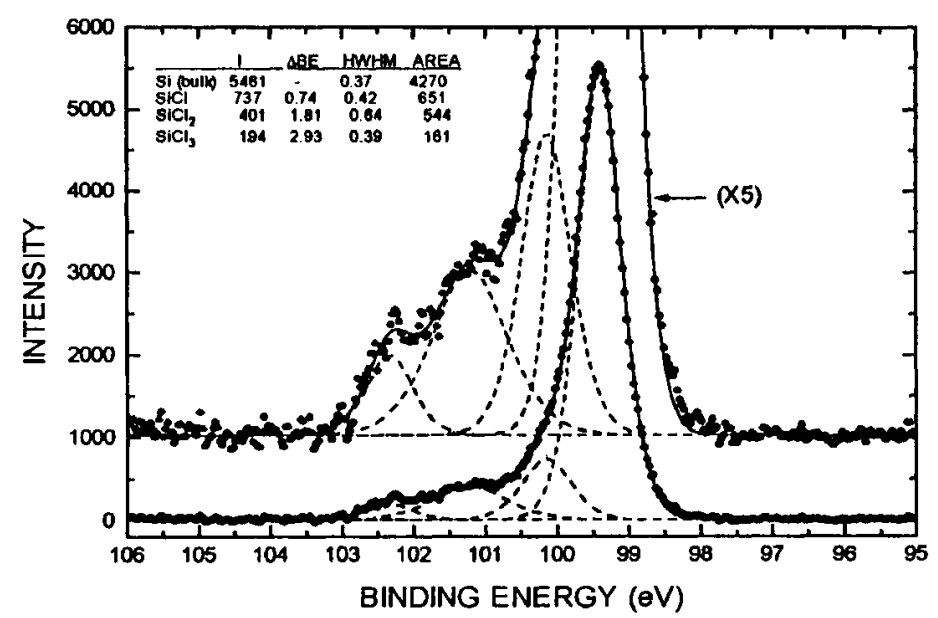

Fig. 1. Si(2p 3/2) XPS spectrum recorded after etching in a $\mathrm{Cl}_{2}$ plasma without laser irradiation. (from ref. 3). The $2 \mathrm{p} 1 / 2$ spin-orbit component has been removed. The relative areas for $\mathrm{SiCl}: \mathrm{SiCl}_{2}: \mathrm{SiCl}_{3}$ are $1.0: 0.84: 0.25$.

The LD-LIF measurements on unmasked $\mathrm{Si}(100)$ samples were performed in-situ during etching. In this process, $15 \mathrm{~ns} \mathrm{XeCl}$ excimer laser pulses rapidly heat the Si surface to near the melting point, causing thermal desorption of $\mathrm{SiCl}$. The tail of the same laser pulse excites $\mathrm{SiCl}$ from the $\mathrm{v}=3,4$ vibrational levels of the ground electronic state to the $v=0$ level of the $\left(B^{2} \Sigma^{+}\right)$state in the gas-phase. Subsequent fluorescence from this state is detected with the monochromator and photomultiplier tube detector. The $\left(\mathrm{B}^{2} \Sigma^{+}\right)$state has a lifetime of $10 \mathrm{~ns}$, so the fluorescence is confined to a region within about $10 \mu \mathrm{m}$ from the surface. The fluorescence spectrum recorded with the plasma on and off are presented in Fig. 2. The strong bands are due to transitions from the $v=0$ level of the $\left(\mathrm{B}^{2} \Sigma^{+}\right)$state to vibrational levels of the ground state. The factor of two increase in signal when the plasma is on is due to an increase in $\mathrm{Cl}$ coverage. Both the plasma on and plasma off signals depend on laser fluence in a manner that suggests a thermal desorption process. They have distinct threshold fluences and they 


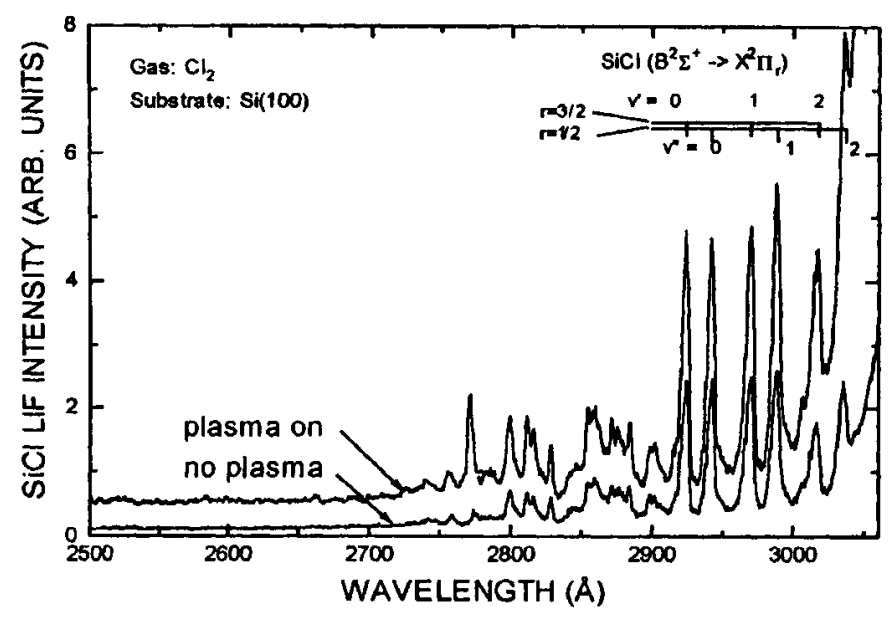

Fig. 2. Steady-state LD-LIF spectra (from ref. 3) recorded during exposure of $\mathrm{Si}(100)$ to $\mathrm{Cl}_{2}$ gas (no plasma, bottom trace) and a $280 \mathrm{~W}$ plasma (top trace).

saturate at fluences above about $0.5 \mathrm{~J} / \mathrm{cm}^{2}$. The threshold fluence for the signal with the plasma on $(0.15$ $\left.\mathrm{J} / \mathrm{cm}^{2}\right)$ is lower than that observed with the plasma off $\left(0.35 \mathrm{~J} / \mathrm{cm}^{2}\right)$, indicating that a more weakly bound layer forms when $\mathrm{Si}(100)$ is exposed to a $\mathrm{Cl}_{2}$ plasma. These layers (plasma on or off) are stable after the laser desorption is interrupted, the plasma is extinguished and gas pumped away, and the laser irradiation is resumed minutes later. The LD-LIF signals observed on the first pulse are close to the respective steady-state levels. Continuous irradiation under these conditions leads to a rapid decay of signal to an undetectable level. Roughly $1 / \mathrm{e}$ of the $\mathrm{Cl}$ is removed per laser pulse. These observations suggest that the $\mathrm{SiCl}_{\mathrm{X}}$ adsorbed layer is stable after the plasma is extinguished, so the XPS analysis in Fig. 1 is indicative of the steady-state surface during etching.

The $\mathrm{SiCl}$ LIF signal is proportional to Cl-coverage as verified by XPS. This was shown by transferring samples to the analysis chamber after exposure to the plasma (no laser irradiation for the last segment of the exposure), or after exposure to the laser and $\mathrm{Cl}_{2}$ with no plasma. The $\mathrm{Cl}(2 \mathrm{p})$-to- $\mathrm{Si}(2 \mathrm{p})$ ratio was $1.9 \mathrm{X}$ higher after plasma exposure than with just exposure to the laser and $\mathrm{Cl}_{2}$, in good agreement with the 2.2-fold increase in the LD-LIF signal when the plasma is on. Thus, at low laser repetition rates the LD-LIF method provides an instantaneous measure of chlorine coverage at steady state. Cl-coverage was measured as a function of discharge power, pressure, and bias voltage. The power dependence is reproduced in Fig. 3. The total Cl-coverage increases rapidly with power and reaches a saturated level at a substantially lower power than does the etch rate or ion flux (saturated ion current in Fig. 3). This is ascribed to the increase in the formation of $\mathrm{Cl}$-atoms with increasing power, which is shown elsewhere to depend on power in a similar manner. (8) The etch rate increases both with $\mathrm{Cl}$-coverage and ion flux at low power, and then is proportional to ion flux at the higher powers that at more typical of standard conditions in commercial high-density plasmas. Consequently, the etch rate under these latter conditions is limited by the ion-bombardment removal of product rather than by the supply of $\mathrm{Cl}$ to the surface. This is further supported by a pressure-independent $\mathrm{Cl}$-coverage and etch rate as a function of pressure $(0.6-20 \mathrm{mTorr})$.

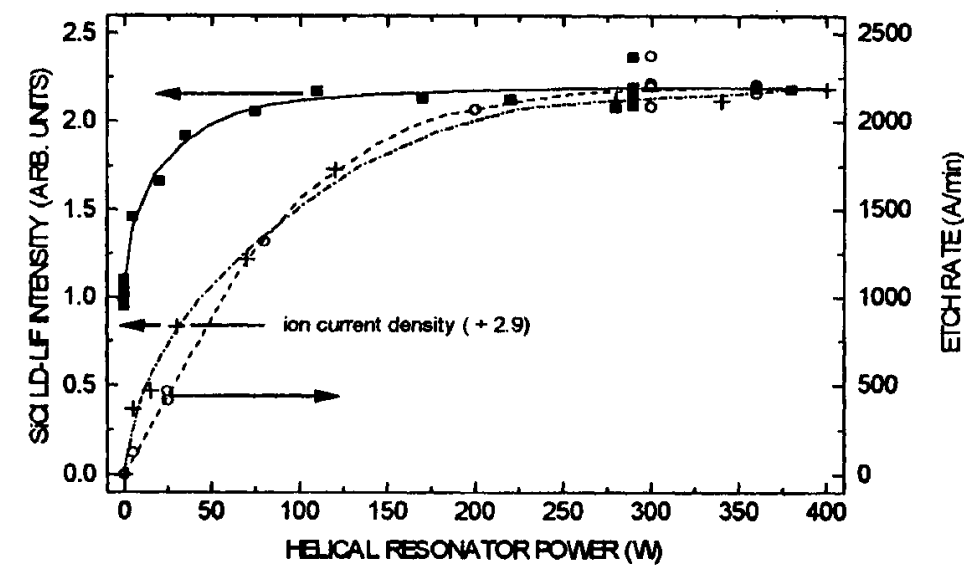

Fig. 3. LD-LIF signal intensity ( 1 arb. unit $=5 \times 10^{14} \mathrm{Cl} / \mathrm{cm}^{2}$ ), saturated ion current, and $\mathrm{Si}$ etch rate $v$ s. $\mathrm{Cl}_{2}$ discharge power (from ref. 3). 
Si (100) ETCHING IN A Cl ${ }_{2}$ HELICAL RESONATOR PLASMA

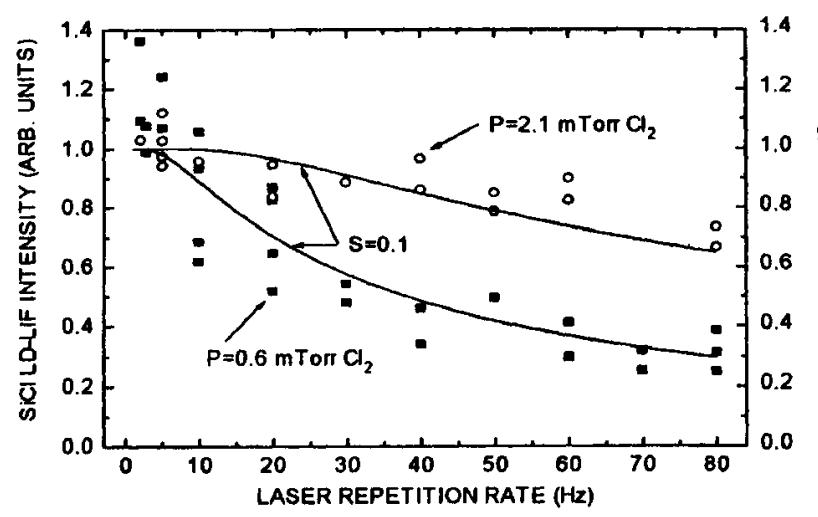

Fig. 4. LD-LIF signal intensity (converted to Cl-coverage on the right-hand axis) vs. laser repetition rate during $\mathrm{Cl}_{2}$ plasma etching of $\mathrm{Si}(100)$ (adapted from ref. 3).

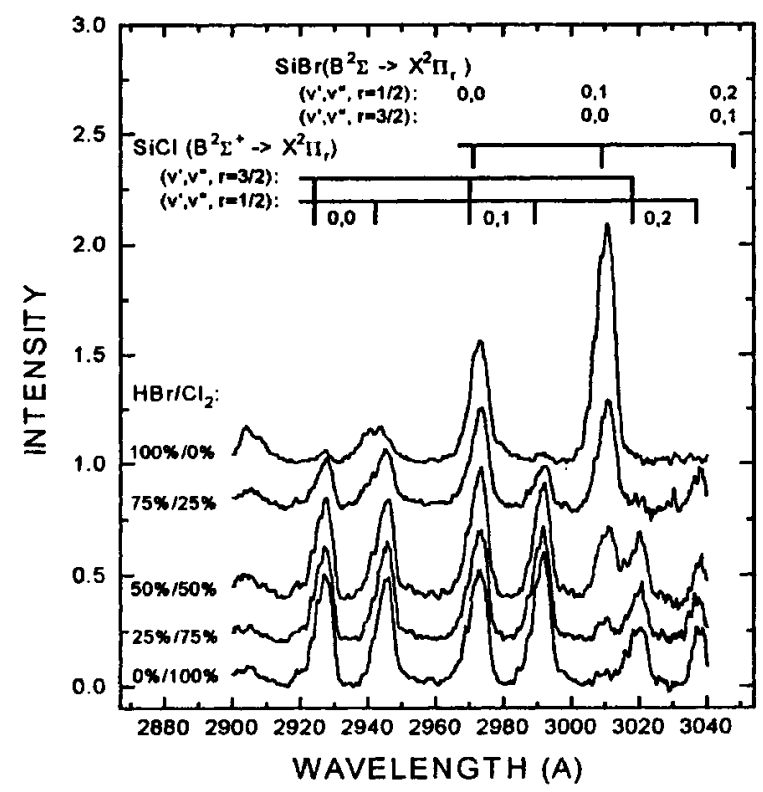

Fig. 5. LD-LIF spectra of $\mathrm{SiCl}$ and $\mathrm{SiBr}$ in $\mathrm{Cl}_{2} / \mathrm{HBr}$ plasmas as a function of gas ratio during plasma etching of $\mathrm{Si}(100)$ (from ref. 4 ).

At high laser repetition rates, the approach to steady state $\mathrm{Cl}$-coverage can be followed. A plot of $\mathrm{Cl}$-coverage as a function of repetition rate is shown in Fig. 4 for two pressures. At low pressure and high repetition rate the laser irradiation is removing $\mathrm{Cl}$ faster than the plasma can supply it. A first-order rate coefficient of $8.1 \times 10^{4} \mathrm{~s}^{-1}$ Torr $^{-1}$ was derived from the dependence of the LD-LIF signal on laser repetition rate and pressure. This indicates that chlorination occurs rapidly with respect to the time required to etch one monolayer, at pressures as low as $0.5 \mathrm{mT}$ Trr. The predominant species impinging on the surface is believed to be $\mathrm{Cl}$-atoms (8). If we ignore the other chlorine species, then using a simple Langmuir adsorption model, we can derive a sticking coefficient of $\sim 0.1$ (fits indicated by the solid curves in Fig. 4).

In $\mathrm{HBr}$-containing plasmas, an analogous detection scheme can be used to detect $\mathrm{SiBr}$ by LDLIF, providing a measure of $\mathrm{Br}$ coverage (4). In mixed $\mathrm{Cl}_{2} / \mathrm{HBr}$ plasmas, both species can be detected simultaneously, as shown in Fig. 5 . In $\mathrm{Cl}_{2} / \mathrm{HBr}$ plasmas, the coverages of $\mathrm{Cl}$ and $\mathrm{Br}$ are simply proportional to the total respective halogen content of the feed gas. The total halogen coverage decreases with increasing $\mathrm{HBr}$, reaching a saturated $\mathrm{Br}$ coverage in pure $\mathrm{HBr}$ plasmas of $0.6 \mathrm{X}$ the saturated $\mathrm{Cl}$-coverage in $\mathrm{Cl}_{2}$ plasmas. The similar reduction in the etch rate in $\mathrm{HBr}$ plasmas is likely due to this reduced halogen coverage.

\section{REFERENCES}

1. K. Nishikawa, K. Ono, M. Tidu, T. Oomori, and K. Namba, 1994 Dry Process Symposium, pp. 105109.

2. I. P. Herman, V. M. Donnelly, K. V. Guinn, and C. C. Cheng, Phys. Rev. Lett. 72, 2801 (1994).

3. C. C. Cheng, K. V. Guinn, V. M. Donnelly, and I. P. Herman, J. Vac. Sci. Technol. A 12, 2630 (1994).

4. C. C. Cheng, K. V. Guinn, I. P. Herman, and V. M. Donnelly, J. Vac. Sci. Technol. A 13, 1970 (1995).

5. K. V. Guinn and V. M. Donnelly, J. Appl. Phys. 75, 2227 (1994).

6. K. V. Guinn, C. C. Cheng, and V. M. Donnelly, J. Vac. Sci. Technol. B 13, 214 (1995).

7. G. S. Oehrlein, K. K. Chan, M. A. Jaso, and G. W. Rubloff, J. Vac. Sci. Technol. A 7, 1030 (1989).

8. V. M. Donnelly, to be published.

a) Also with the Department of Applied Physics and the Columbia Radiation Laboratory, Columbia University, New York, NY 10027.

b) Present address: Gasonics International, 2730 Junction Ave., San Jose, CA 95134. 